\title{
Ankle—brachial index, vascular calcifications and mortality in dialysis patients
}

\author{
Teresa Adragao ${ }^{1}$, Ana Pires $^{2}$, Patrícia Branco ${ }^{3}$, Rui Castro ${ }^{4}$, Ana Oliveira ${ }^{5}$, Cristina Nogueira ${ }^{6}$, \\ Joaquim Bordalo ${ }^{7}$, José Dias Curto ${ }^{8}$ and Mateus Martins Prata ${ }^{9}$
}

\begin{abstract}
${ }^{1}$ Diaverum, Unidade do Estoril, Portugal, ${ }^{2}$ Diaverum, Unidade de Linda-a-Velha, Portugal, ${ }^{3}$ Diaverum, Sociedade Portuguesa de Diálise, Amadora, Portugal, ${ }^{4}$ TECSAM, Vila Real, Portugal, ${ }^{5}$ Diaverum, Unidade de Paredes, Portugal, ${ }^{6}$ Diaverum, Unidade de Torres Vedras, Portugal, ${ }^{7}$ Diaverum, Unidade do Lumiar, Lisbon, Portugal, ${ }^{8}$ ISCTE, Business School, Lisbon, Portugal and ${ }^{9}$ Diaverum, Senior Scientific Consultant and former Country Medical Director, Portugal

Correspondence and offprint requests to: Teresa Adragao; E-mail: tadragao@netcabo.pt
\end{abstract}

\begin{abstract}
Background. The ankle-brachial index (ABI) is a noninvasive method to evaluate peripheral artery disease (PAD). $\mathrm{ABI}<0.9$ diagnoses $\mathrm{PAD} ; \mathrm{ABI}>1.3$ is a false negative caused by noncompressible arteries. The aim of this study is to evaluate the association between ABI with vascular calcifications (VC) and with mortality, in haemodialysis (HD) patients.

Methods. We studied 219 HD patients (60\% male; $20 \%$ diabetic). At baseline, ABI was evaluated by a Doppler device. VCs were evaluated by two methods: the abdominal aorta calcification score (AACS) in a lateral plain X-ray of the abdominal aorta and the simple vascular calcification score (SVCS) in plain X-rays of the pelvis and hands. VC were also classified by their anatomical localization in main vessels (aorta and iliac-femoral axis) and in peripheral or distal vessels (pelvic, radial or digital). The cutoff values for the different VC scores in relation with ABI were determined by receiver operating characteristic curve analysis. Biochemical parameters were time averaged for the 6 months preceding $\mathrm{ABI}$ evaluation.
\end{abstract}

Results. An ABI $<0.9$, an $\mathrm{ABI}>1.3$ or a normal $\mathrm{ABI}$ were found, respectively, in $90(41 \%)$, in $42(19 \%)$ and in $87(40 \%)$ patients. AACS $\geq 6$ and SVCS $>3$ were found, respectively, in $98(45 \%)$ and $95(43 \%)$ patients. The adjusted odds ratio (OR) for having an $\mathrm{ABI}<0.9$ was $2.5(\mathrm{P}=0.007)$ for AACS $\geq 6$ and $4.5(\mathrm{P}<0.001)$ for iliac-femoral calcification score $(\mathrm{CS}) \geq 2$. The adjusted OR for having an $\mathrm{ABI}>1.3$ was $4.2(\mathrm{P}=0.003)$ for pelvic $\mathrm{CS}$ and $3.7(\mathrm{P}=0.006)$ for hand $\mathrm{CS} \geq 2$. During an observational period of 28.9 months, all-cause and cardiovascular mortality occurred, respectively, in 50 (23\%) and in $29(13 \%)$ patients. Adjusting for age, diabetes, $\mathrm{P}$ levels, HD duration and cardiovascular disease at baseline, an $\mathrm{ABI}<0.9$ [hazard ratio $(\mathrm{HR})=3.9, \mathrm{P}<0.001$ ] and an $\mathrm{ABI}>1.3(\mathrm{HR}=2.7, \mathrm{P}=0.038)$ were associated with allcause mortality; an ABI $<0.9(\mathrm{HR}=7.2, \mathrm{P}=0.002)$ and an $\mathrm{ABI}>1.3(\mathrm{HR}=5.1, \mathrm{P}=0.028)$ were associated with cardiovascular mortality.
Conclusions. Both low and high ABI were independent predictors of all-cause and cardiovascular mortality. VC in main arteries were associated with an $\mathrm{ABI}<0.9$. VC in peripheral and distal arteries were associated with an $\mathrm{ABI}$ $>1.3$. ABI is a simple and noninvasive method that allows the identification of high cardiovascular risk patients.

Keywords: ankle-brachial index; CKD 5D; mortality; vascular calcifications

\section{Introduction}

Peripheral artery disease (PAD) is highly prevalent in dialysis patients but is frequently underdiagnosed. In haemodialysis (HD) patients, traditional risk factors such as age and diabetes but also nontraditional risk factors such as hypercalcaemia and hyperphosphataemia have been associated with higher risk of amputation, suggesting a contributory role of vascular calcifications (VC) for PAD in this population [1]. Ankle-brachial index (ABI) is a simple and noninvasive method that may be useful to identify PAD. In general, population measurement of ABI may improve the accuracy of cardiovascular risk prediction [2]. In dialysis patients, low or high ABI have already been associated with higher risk of death [3-5]; low ABI has been associated with vascular access failure [6]. Low ABI $(<0.9)$ identifies obstructive artery disease, while high $\mathrm{ABI}(>1.3)$ is caused by stiff noncompressible distal arteries, probably in relation with distal arteries calcification [7]. The objective of this study is to evaluate the prevalence of an abnormal $\mathrm{ABI}$ in a group of dialysis patients and to analyse the association of low or high $\mathrm{ABI}$ with $\mathrm{VC}$ and with mortality.

\section{Study design}

This study is a cross-sectional analysis performed in a group of prevalent HD patients that were submitted to evaluation of the ABI and VC at the study baseline. Patients were followed prospectively during a mean observational 
period of $28.9 \pm 6.8$ (17-36) months in order to evaluate the association of low or high ABI with all-cause mortality. This protocol was approved by the Institutional Ethic Committee and all patients provided informed consent.

\section{Study population}

Seven HD clinics participated in this study. In each clinic, 20-40 patients were randomly selected using a central selection method generated by a computer programme. Exclusion criteria were age $<18$ years, lower limb bilateral amputation or patient incapacity to give informed consent. ABI was evaluated in 257 patients and marked the beginning of the study for each patient. Complete data available for analysis was gathered in 219 patients who constituted the sample for this study. The main demographic, biochemical and clinical characteristics of the whole sample are presented in Table 1 . There were 131 male $(60 \%)$ and 43 diabetic patients $(20 \%)$. Mean age was $65 \pm 15$ years and mean HD duration was $82 \pm 74$ months. Diagnosis of vascular disease at baseline was provided by the attending physician, based on clinical criteria and diagnostic exams according to the standard of care. Coronary artery disease (CAD) was diagnosed if the patient had a positive stress test, had suffered an acute coronary syndrome or a myocardial infarction or had been submitted to a percutaneous coronary intervention or coronary bypass surgery. PAD was considered if there was claudication, ischaemic ulcers, lower limb amputation, revascularization or previous diagnosis of obstruction by ultrasonography or angiography. Based on these criteria, CAD and PAD were identified, respectively, in 77 (35\%) and in 51 (25\%) patients. Baseline cardiovascular disease (CAD or PAD) was diagnosed in $88(40 \%)$ patients. During an observational period of $28.9 \pm 6.8$ months, 50 patients $(23 \%)$ died. The main causes of death were: cardiovascular in 29 patients, infectious in 14 patients and other causes in 7 patients (neoplasia in 3 patients, cachexia in 3 patients and haemorrhagic shock in 1 patient). No patient was lost for follow-up.

\section{Methods}

\section{Vascular calcifications}

$\mathrm{VC}$ were evaluated in plain X-ray by two different methods: the abdominal aorta calcification score (AACS) and the simple vascular calcification score (SVCS). The AACS, ranging from 0 to 24, was evaluated in the lateral abdominal aorta from L1 to L4 using a methodology previously described by Kauppila et al. [8]. The SVCS ranging from 0 to 8 was developed by us and is evaluated in plain X-ray of pelvis and hands [9]. AACS and SVCS were evaluated separately by two experienced clinicians without the knowledge of clinical information. Since increase in ABI is caused by noncompressible arteries that may be produced by calcification in distal arteries, we used the information obtained by these two scores to further classify VC by anatomical criteria in calcification in large arteries (aorta and iliac-femoral axis) and in peripheral and distal arteries (branches

Table 1. Demographic, biochemical and clinical factors ${ }^{\mathrm{a}}$

\begin{tabular}{|c|c|c|c|c|c|c|}
\hline $\mathrm{ABI}, N(\%)$ & $\begin{array}{l}\text { All patients, } \\
N=219\end{array}$ & $\begin{array}{l}\mathrm{ABI}<0.9 \\
N=90(41 \%)\end{array}$ & $\mathrm{P}$ & $\begin{array}{l}\text { ABI } 0.9-1.3, \\
N=87(40 \%)\end{array}$ & $\begin{array}{l}\mathrm{ABI}>1.3 \\
N=42(19 \%)\end{array}$ & $\mathrm{P}$ \\
\hline Age (years) & $65 \pm 15$ & $69 \pm 13 * *$ & $<0.001$ & $60 \pm 16$ & $67 \pm 13^{*}$ & 0.013 \\
\hline HD duration (months) & $82 \pm 74$ & $85 \pm 73$ & 0.685 & $89 \pm 81$ & $63 \pm 61 *$ & 0.039 \\
\hline Male gender $(N, \%)$ & $131(60 \%)$ & $59(66 \%)$ & 0.086 & $46(53 \%)$ & $26(62 \%)$ & 0.333 \\
\hline Diabetes $(N, \%)$ & $43(20 \%)$ & $20(22 \%)$ & 0.094 & $11(13 \%)$ & $12(29 \%)^{*}$ & 0.027 \\
\hline Smoking habits $(N, \%)$ & $47(22 \%)$ & $23(26 \%)$ & 0.178 & $15(17 \%)$ & $9(21 \%)$ & 0.567 \\
\hline $\mathrm{Kt} / \mathrm{V}$ & $1.8 \pm 0.3$ & $1.8 \pm 0.3$ & 0.229 & $1.8 \pm 0.3$ & $1.7 \pm 0.3^{*}$ & 0.012 \\
\hline $\mathrm{Hb}(\mathrm{g} / \mathrm{dL})$ & $11.9 \pm 1.4$ & $11.9 \pm 1.4$ & 0.955 & $11.9 \pm 1.3$ & $11.9 \pm 1.2$ & 0.658 \\
\hline Albumin (g/dL) & $4.1 \pm 0.6$ & $4.1 \pm 0.3$ & 0.058 & $4.2 \pm 0.8$ & $4.1 \pm 0.4$ & 0.317 \\
\hline $\mathrm{CRP}(\mathrm{mg} / \mathrm{dL})$ & $1.2 \pm 1.7$ & $1.2 \pm 1.3$ & 0.607 & $1.3 \pm 2.3$ & $1.1 \pm 1.2$ & 0.502 \\
\hline $\mathrm{Ca}(\mathrm{mg} / \mathrm{dL})$ & $8.9 \pm 0.7$ & $8.9 \pm 0.6$ & 0.943 & $8.9 \pm 0.7$ & $8.9 \pm 0.6$ & 0.821 \\
\hline $\mathrm{P}(\mathrm{mg} / \mathrm{dL})$ & $4.9 \pm 1.2$ & $4.8 \pm 1.2$ & 0.505 & $4.9 \pm 1.2$ & $4.7 \pm 1.0$ & 0.288 \\
\hline iPTH $(\mathrm{pg} / \mathrm{mL})$ & $319 \pm 340$ & $358 \pm 446$ & 0.261 & $298 \pm 209$ & $281 \pm 294$ & 0.709 \\
\hline Total cholesterol (mg/dL) & $165 \pm 38$ & $166 \pm 36$ & 0.820 & $167 \pm 39$ & $157 \pm 38$ & 0.164 \\
\hline HDL-C (mg/dL) & $44 \pm 11$ & $43 \pm 10$ & 0.278 & $44 \pm 11$ & $47 \pm 11$ & 0.314 \\
\hline Triglycerides (mg/dL) & $166 \pm 104$ & $163 \pm 94$ & 0.202 & $184 \pm 124$ & $132 \pm 72 *$ & 0.013 \\
\hline Pulse pressure (mmHg) & $65 \pm 15$ & $69 \pm 14^{* *}$ & $<0.001$ & $61 \pm 14$ & $64 \pm 16$ & 0.263 \\
\hline $\mathrm{CaCO} 3(N) \mathrm{g} /$ day & (74) $2.3 \pm 1.4$ & (30) $2.3 \pm 1.5$ & 0.872 & (28) $2.4 \pm 1.3$ & (16) $2.1 \pm 1.3$ & 0.577 \\
\hline Sevelamer $(N) \mathrm{g} /$ day & (114) $4.1 \pm 2$ & (46) $4.0 \pm 1.8$ & 0.588 & (49) $4.2 \pm 2.3$ & (19) $4.0 \pm 1.6$ & 0.681 \\
\hline Cinacalcet $(N) \mathrm{mg} /$ day & (44) $46.7 \pm 30.8$ & (14) $53.5 \pm 41$ & 0.482 & (23) $45.6 \pm 26$ & (7) $36.4 \pm 17$ & 0.403 \\
\hline Alfacalcidol $(N) \mu \mathrm{g} /$ week & (20) $2.3 \pm 1.7$ & (7) $2.3 \pm 1.2$ & 0.247 & (6) $1.6 \pm 0.9$ & (7) $2.8 \pm 2.6$ & 0.297 \\
\hline Paricalcitol $(N) \mu \mathrm{g} /$ week & (47) $3.1 \pm 1.7$ & (17) $2.5 \pm 1.3$ & 0.102 & (17) $3.5 \pm 1.8$ & (13) $3.1 \pm 2.0$ & 0.625 \\
\hline AACS median (IQR) & $4(9)$ & $7(\mathbf{1 0}) * *$ & $<0.001$ & $3(7)$ & $4(5)$ & 0.164 \\
\hline SVCS median (IQR) & $3(4)$ & $3(4) * *$ & $<0.001$ & $1(4)$ & $2.5(4)^{*}$ & 0.040 \\
\hline PAD (baseline) $(N, \%)$ & $51(23 \%)$ & $38(42 \%)^{* *}$ & $<0.001$ & $7(8 \%)$ & $6(14 \%)$ & 0.270 \\
\hline CAD (baseline) $(N, \%)$ & $77(35 \%)$ & $34(38 \%)$ & 0.202 & $25(29 \%)$ & $18(43 \%)$ & 0.111 \\
\hline CVD (baseline) $(\mathrm{N}, \%)$ & $88(40 \%)$ & $40(44 \%)$ & 0.094 & $28(32 \%)$ & $20(48 \%)$ & 0.089 \\
\hline All-cause mortality $(N, \%)$ & $50(23 \%)$ & $31(34 \%)^{* *}$ & $<0.001$ & $9(10 \%)$ & $10(24 \%)^{*}$ & 0.043 \\
\hline $\mathrm{CV}$ mortality $(N, \%)$ & $29(13 \%)$ & $20(22 \%)^{* *}$ & $<0.001$ & $3(3 \%)$ & $6(14 \%)^{*}$ & 0.024 \\
\hline
\end{tabular}

${ }^{a} \mathrm{CRP}, \mathrm{C}$-reactive protein; iPTH, intact PTH; HDL-C, high-density lipoprotein cholesterol; IQR, interquartile range; CVD, cardiovascular disease; CV, cardiovascular. low ABI $(<0.9)$ and high ABI $(>1.3)$ are compared with normal ABI $(0.9-1.3)$ : $t$-test for parametric continuous variables, KruskalWallis for nonparametric variables and Pearson chi-square for categorical variables $(* \mathrm{P}<0.05 * * \mathrm{P}<0.001)$. Significant $\mathrm{P}$ values $(<0.05)$ are presented in bold. 
of the internal iliac artery evaluated in pelvis plain X-ray and radial and digital arteries evaluated in plain X-ray of hands). We intended to analyse the association of these types of $\mathrm{VC}$, defined by anatomical criteria, with low or high ABI.

Evaluation of $A B I$

ABI was evaluated with the help of a manual Doppler device (MD6 bidirectional Doppler from Hokanson). After placing the patient in a supine position for $5 \mathrm{~min}$, the systolic blood pressure (SBP) was evaluated in the brachial artery of the arm without vascular access and in the posterior tibial artery or dorsal pedal artery of the right and left lower limb. Following a clockwise rotation, two separate measures of the SBP were obtained in each site. The mean SBP value for each site was used for calculating right and left $\mathrm{ABI}$ with the following formula: $\mathrm{ABI}=$ ankle $\mathrm{SBP} /$ brachial SBP. Normal ABI was defined by normal values $(0.9-1.3)$ detected in both sides. Low $\mathrm{ABI}$ was defined by an $\mathrm{ABI}<0.9$ in one or both sides. High $\mathrm{ABI}$ corresponded to $\mathrm{ABI}>1.3$ in both sides or in one side with normal $\mathrm{ABI}$ in the contralateral side. According to these results, patients were divided in three groups for analysis: low ABI $(<0.9)$ in 90 patients (41\%), normal ABI (0.9-1.3) in 87 patients $(40 \%)$ and high ABI $(>1.3)$ in 42 patients (19\%). Two experienced technicians performed this evaluation using the same device. Inter-operator agreement in the diagnosis of low, normal or high ABI was $88.8 \%$, kappa $=0.79 \pm 0.074$.

\section{Biochemical analysis}

Mid-week Kt/V and predialysis serum levels of the following biochemical parameters were evaluated and time averaged for the 6 months preceding the evaluation of $\mathrm{ABI}: \mathrm{Kt} / \mathrm{V}, \mathrm{Ca}, \mathrm{P}$, albumin and $\mathrm{C}$-reactive protein. Total intact parathormone (PTH) was evaluated every 3 months by immunochemiluminescence using two second-generation assays, from Roche Diagnostics, Basel, Switzerland and from Abbott, Barcelona, Spain. Total cholesterol, high-density lipoprotein cholesterol, low-density lipoprotein (LDL) cholesterol and triglycerides were evaluated twice.

\section{Statistical analysis}

Data are presented as frequencies for categorical variables, mean values with SD for continuous variables and median values with interquartile range for ordinal variables. Comparison between groups was performed by the independent samples $t$-test, Kruskal-Wallis, Pearson chi-square and Fisher exact test when appropriate. Correlation was performed using Spearman's rho correlation. Survival curves were estimated by Kaplan-Meier analysis and compared by the log-rank test. In separate models, the association of low or high ABI with all-cause mortality was evaluated with Cox regression in unadjusted and adjusted models using the enter method. Association of low or high ABI with VC and association of PAD with VC and ABI were evaluated in binary logistic regression in unadjusted and adjusted models using the enter method. The absence of colinearity among explanatory factors was checked in all models based on variance inflation factor and variance proportions standard procedures.

Receiver operating characteristic (ROC) curve analysis allowed the identification of the best cutoff values for the $\mathrm{VC}$ scores in relation with low or high $\mathrm{ABI}$. In relation with $\mathrm{ABI}<0.9$, the best cutoff value for aortic calcification was $\geq 6$ [area under the curve (AUC) $=0.656$; $95 \%$ confidence interval (CI), 0.581-0.726] and for iliac-femoral calcification was $>2(\mathrm{AUC}=0.763 ; 95 \% \mathrm{CI} 0.693-0.823)$. In relation with $\mathrm{ABI}>1.3$, the best cutoff value for peripheral pelvic calcification was $\geq 2$ (AUC $=0.630$; $95 \%$ CI $0.541-0.741$ ) and for hands calcification was $\geq 2$ (AUC $=0.596$; 95\% CI 0.506-0.682).

Statistical analyses were performed with the SPSS system 17.0 (SPSS Inc., Chicago, IL) and with the Medcalc program version 6.0 (Medcalc software, Mariakerke, Belgium). For all comparisons and statistical tests, a P-value $<0.05$ implied the rejection of the null hypothesis and the result was considered statistically significant.

\section{Results}

\section{Descriptive statistics}

In this group of 219 patients, an $\mathrm{ABI}<0.9$ and $>1.3$ were present, respectively, in 90 (41\%) and in 42 (19\%) patients. Normal ABI $(\geq 0.9$ and $\leq 1.3)$ was present in 87
(40\%) patients. VC in the abdominal aorta (AACS) were verified in $165(75 \%)$ patients. The SVCS detected VC in $154(70 \%)$ patients. VC in iliac-femoral axis, pelvic peripheral arteries and in hands arteries were detected, respectively, in $132(60 \%), 55(25 \%)$ and $87(40 \%)$ patients. SVCS was correlated with AACS (rho= $0.694, \mathrm{P}<0.001)$. An AACS $\geq 6$ and an SVCS $>3$ were present, respectively, in $98(45 \%)$ and 95 (43\%) patients. By ROC curve analysis, an SVCS $>3$ identified an AACS $\geq 6$ with $78 \%$ sensitivity and $81 \%$ specificity $(\mathrm{AUC}=0.845 ; 95 \%$ CI $0.791-0.891)$. In univariate analysis (Table 1), patients with lower ABI compared with normal ABI showed older age $(\mathrm{P}<0.001)$, higher pulse pressure $(\mathrm{P}<0.001)$, higher AACS $(\mathrm{P}<0.001)$, higher SVCS $(\mathrm{P}<0.001)$ and higher all-cause $(\mathrm{P}<0.001)$ and cardiovascular mortality $(\mathrm{P}<0.001)$. Patients with higher ABI compared to normal ABI were older $(\mathrm{P}=$ $0.013)$, with higher pulse pressure $(P=0.039)$, higher SVCS $(P=0.040)$ and had higher all-cause $(P=0.043)$ and cardiovascular mortality $(\mathrm{P}=0.024)$.

\section{Association of $A B I$ with $V C$}

Binary logistic regression with the enter method in unadjusted and adjusted models (Figure 1 and Table 2) demonstrated that $\mathrm{VC}$ in the aorta and in the iliac and femoral arteries were associated with an ABI $<0.9$. Adjusting for age, gender, HD duration, diabetes, smoking habits, $\mathrm{Ca}, \mathrm{P}$ and LDL levels, an AACS $\geq 6$ [odds ratio $(\mathrm{OR})=2.52 ; 95 \%$ CI $1.28-4.96 ; \mathrm{P}=0.007]$ and an iliacfemoral calcification score $(\mathrm{CS}) \geq 2(\mathrm{OR}=4.45 ; 95 \%$ CI 2.12-9.35; $\mathrm{P}<0.001)$ were associated with an ABI $<0.9$.

In unadjusted and adjusted models, VC in pelvic peripheral arteries and in hands radial and digital arteries were associated with $\mathrm{ABI}>1.3$ (Figure 2 and Table 3 ). Adjusting for age, gender, HD duration, diabetes, smoking habits, $\mathrm{Ca}, \mathrm{P}$ and LDL levels, a pelvic $\mathrm{CS} \geq 2(\mathrm{OR}=$ $4.21 ; 95 \%$ CI 1.61-11.1; $\mathrm{P}=0.003)$ and hands $\mathrm{CS} \geq 2$ $(\mathrm{OR}=3.74 ; 95 \%$ CI $1.45-9.68 ; \mathrm{P}=0.006)$ were associated with an $\mathrm{ABI}>1.3$.

There was no association between VC in pelvic peripheral arteries or with radial and digital hand arteries with ABI $<0.9$ (Figure 1). There was no association between calcifications in main arteries (aorta and iliac-femoral arteries) with an $\mathrm{ABI}>1.3$ (Figure 2).

\section{Association of clinical PAD with $V C$ and $A B I$}

PAD was present, at baseline, in $51(25 \%)$ patients. In univariate analysis (Table 4), patients with PAD, when compared with patients without PAD, showed more VC evaluated in the main vessels: AACS $(\mathrm{P}=0.001)$; SVCS $(\mathrm{P}<$ $0.001)$ and iliac-femoral calcifications $(\mathrm{P}<0.001)$. Patients with PAD when compared with patients without PAD had a higher prevalence of $\mathrm{ABI}<0.9(\mathrm{P}<0.001)$ and a lower prevalence of ABI $0.9-1.3(\mathrm{P}<0.001)$. Binary logistic regression (Table 5) with the enter method in unadjusted and adjusted models showed that ABI $<0.9$, ABI 0.9-1.3, AACS $\geq 6$, SVCS $\geq 3$ and ileo-femoral $\mathrm{CS} \geq 2$ were associated with clinical PAD. Adjusting for age, gender, HD duration, 


\section{Association of $A B I<0.9$ with vascular calcifications}

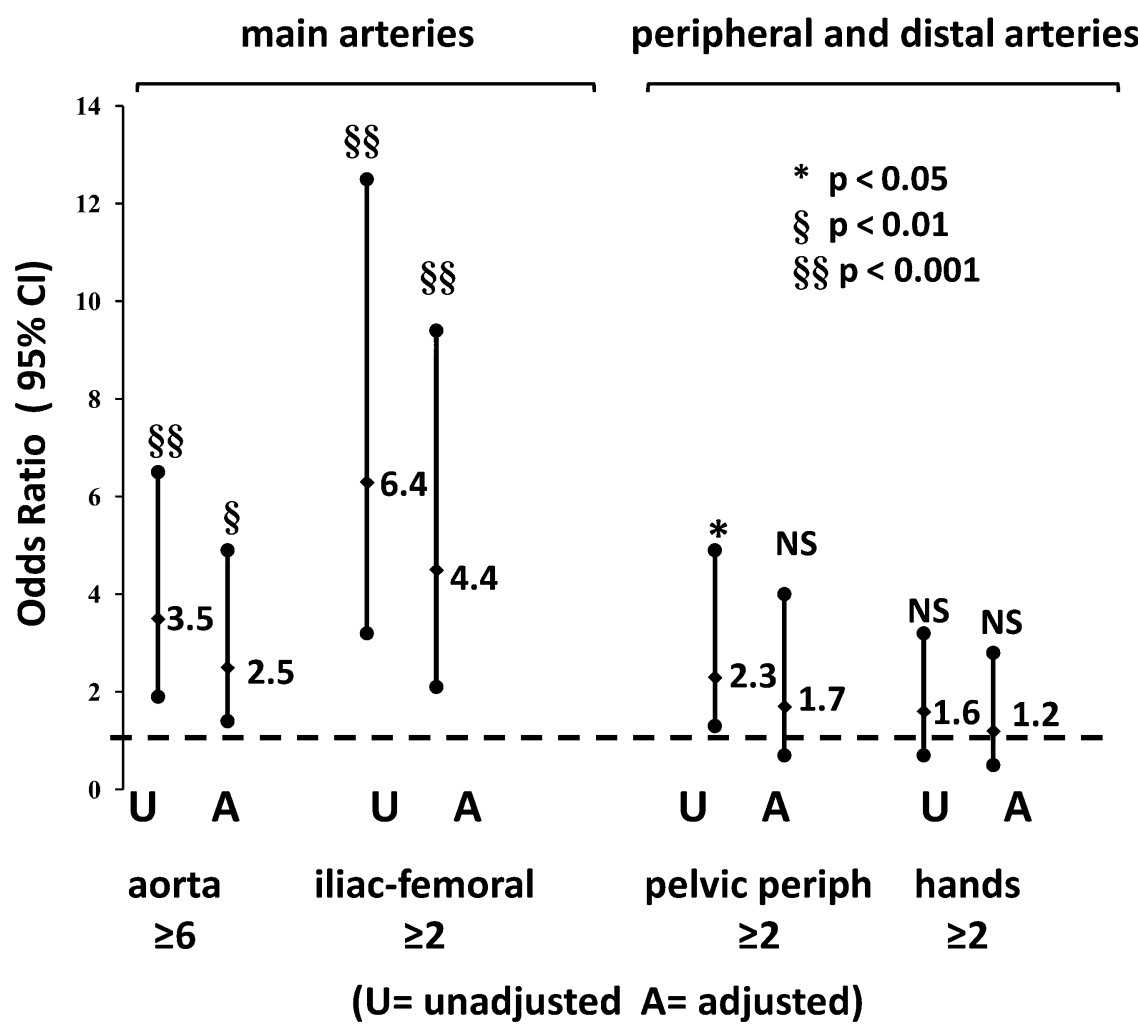

Fig. 1. $\mathrm{ABI}<0.9$ and vascular calcifications

Table 2. Association of VCs in main arteries with $\mathrm{ABI}<0.9$ binary regression $^{\mathrm{a}}$

\begin{tabular}{llllr}
\hline $\begin{array}{l}\text { Dependent variable: } \\
\text { ABI }<0.9\end{array}$ & \multicolumn{1}{c}{ B } & OR & $95 \%$ CI & \multicolumn{1}{c}{$\mathrm{P}$} \\
\hline MODEL 1 & & & & \\
Unadjusted & & & & \\
$\quad$ AACS $\geq 6$ & 1.244 & 3.47 & $1.86-6.45$ & $<\mathbf{0 . 0 0 1}$ \\
Adjusted & & & & \\
AACS $\geq 6$ & 0.926 & 2.52 & $1.28-4.96$ & $\mathbf{0 . 0 0 7}$ \\
Age & 0.039 & 1.04 & $1.01-1.07$ & $\mathbf{0 . 0 0 4}$ \\
Male gender & 0.481 & 1.62 & $0.80-3.26$ & 0.180 \\
HD duration & 0.000 & 1.00 & $0.99-1.00$ & 0.974 \\
Diabetes & 0.613 & 1.85 & $0.77-4.41$ & 0.167 \\
Smoking & 0.523 & 1.68 & $0.71-0.39$ & 0.233 \\
Ca levels & -0.044 & 0.96 & $0.58-1.58$ & 0.863 \\
P levels & 0.083 & 1.08 & $0.81-1.46$ & 0.583 \\
LDL-C & 0.002 & 1.00 & $0.99-1.01$ & 0.687 \\
MODEL 2 & & & & \\
Unadjusted & & & & \\
Iliac-fem $\geq 2$ & 1.853 & 6.38 & $3.23-12.59$ & $<\mathbf{0 . 0 0 1}$ \\
Adjusted & & & & \\
Iliac-fem $\geq 2$ & 1.493 & 4.45 & $2.12-9.35$ & $<\mathbf{0 . 0 0 1}$ \\
Age & 0.032 & 1.03 & $1.00-1.06$ & $\mathbf{0 . 0 2 4}$ \\
Male gender & 0.310 & 1.36 & $0.66-2.81$ & 0.403 \\
HD duration & 0.000 & 0.99 & $0.99-1.01$ & 0.806 \\
Diabetes & 0.309 & 1.36 & $0.55-3.36$ & 0.503 \\
Smoking & 0.545 & 1.72 & $0.71-4.18$ & 0.228 \\
Ca levels & -0.034 & 0.97 & $0.58-1.62$ & 0.898 \\
P levels & 0.072 & 1.07 & $0.79-1.45$ & 0.639 \\
LDL-C & 0.002 & 1.00 & $0.99-1.01$ & 0.735 \\
\hline
\end{tabular}

${ }^{a}$ Iliac-fem, iliac femoral CS. Significant P values $(<0.05)$ are presented in bold. B is the regression coefficient. diabetes, smoking habits, $\mathrm{Ca}, \mathrm{P}$ and LDL levels, an $\mathrm{ABI}$ $<0.9$ (OR $=6.04 ; 95 \%$ CI 2.83-12.86; $\mathrm{P}<0.001$ ), an ABI $0.9-1.3(\mathrm{OR}=0.22 ; 95 \%$ CI $0.9-0.64 ; \mathrm{P}=0.001)$, an $\mathrm{AACS} \geq 6(\mathrm{OR}=2.01 ; 95 \%$ CI $0.99-4.04 ; \mathrm{P}=0.051)$, an $\mathrm{SVCS} \geq 3(\mathrm{OR}=3.13 ; 95 \%$ CI $1.48-6.59 ; \mathrm{P}=0.003)$ and an ileo-femoral $\mathrm{CS} \geq 2(\mathrm{OR}=3.45$; 95\% CI 1.49-8.03; $\mathrm{P}=0.004)$ were associated with clinical PAD. In univariate and multivariate analyses, there was no association between $\mathrm{ABI}>1.3$, pelvic peripheral and hand CS with clinical PAD.

\section{Association of ABI with all-cause and with} cardiovascular mortality

Lower cumulative survival in association with all-cause mortality (Figure 3) was observed in patients with $\mathrm{ABI}<0.9$ (log rank $=20.0 ; \mathrm{P}<0.001)$ and in patients with $\mathrm{ABI}>1.3(\log$ rank $=6.6 ; \mathrm{P}=0.010$ ) when compared with patients with normal ABI. Cardiovascular mortality (Figure 3) was also associated with $\mathrm{ABI}<0.9(\log$ rank $=18.3 ; \mathrm{P}<0.001)$ and with $\mathrm{ABI}>1.3(\log$ rank $=7.5 ; \mathrm{P}=0.006)$.

Cox regression analysis showed, in unadjusted and adjusted models for age, HD duration, diabetes, vascular disease at baseline and P levels, that an ABI $<0.9$ (Table 6) or an ABI >1.3 (Table 7) were associated with all-cause mortality and with cardiovascular mortality. The all-cause mortality-adjusted hazard ratio (HR) was 3.95 (95\% CI $1.83-8.51 ; \mathrm{P}<0.001)$ for $\mathrm{ABI}<0.9$ and $2.71(95 \% \mathrm{CI}$ 1.06-6.93; $\mathrm{P}=0.038$ ) for $\mathrm{ABI}>1.3$, when compared with normal ABI. The cardiovascular mortality adjusted HR was 
Association of $A B I>1.3$ with vascular calcifications

main arteries peripheral and distal arteries

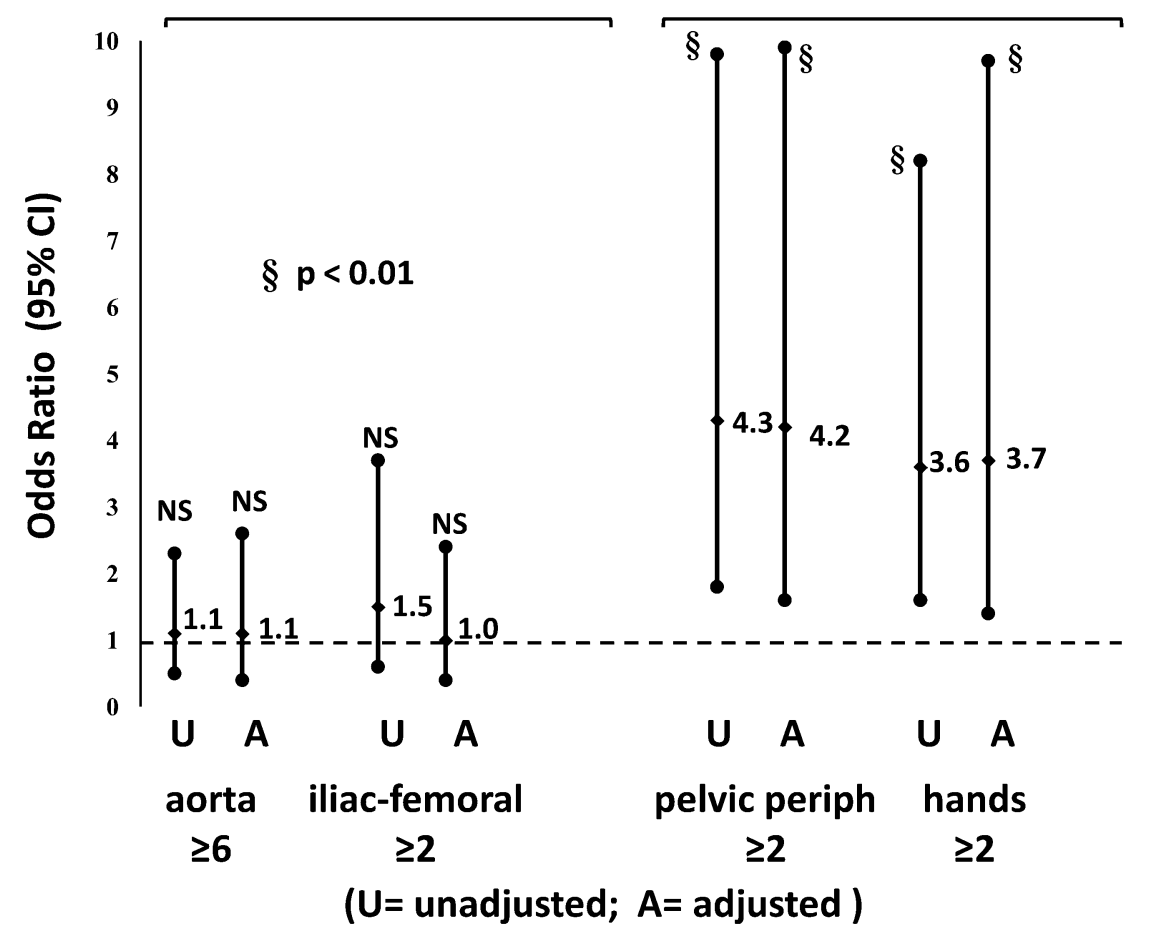

Fig. 2. $\mathrm{ABI}>1.3$ and vascular calcifications

Table 3. Association of $\mathrm{VC}$ in peripheral and distal arteries with ABI $>1.3$ (binary regression) $^{\mathrm{a}}$

\begin{tabular}{|c|c|c|c|c|}
\hline Dependent variable: $\mathrm{ABI}>1.3$ & $B$ & OR & $95 \% \mathrm{CI}$ & $\mathrm{P}$ \\
\hline \multicolumn{5}{|l|}{ MODEL 3} \\
\hline \multicolumn{5}{|l|}{ Unadjusted } \\
\hline Pelvic periph $\geq 2$ & 1.447 & 4.25 & $1.79-10.1$ & 0.001 \\
\hline \multicolumn{5}{|l|}{ Adjusted } \\
\hline Pelvic periph $\geq 2$ & 1.439 & 4.21 & $1.61-11.1$ & 0.003 \\
\hline Age & 0.028 & 1.03 & $0.99-1.06$ & 0.069 \\
\hline Male gender & 0.003 & 1.00 & $0.39-2.56$ & 0.995 \\
\hline HD duration & -0.006 & 0.99 & $0.98-1.00$ & 0.108 \\
\hline Diabetes & 0.519 & 1.68 & $0.59-4.72$ & 0.325 \\
\hline Smoking & 0.333 & 1.39 & $0.47-4.11$ & 0.546 \\
\hline Ca levels & 0.151 & 1.16 & $0.58-2.31$ & 0.664 \\
\hline P levels & -0.071 & 0.93 & $0.62-1.38$ & 0.724 \\
\hline LDL-C & -0.002 & 0.99 & $0.98-1.01$ & 0.722 \\
\hline \multicolumn{5}{|l|}{ MODEL 4} \\
\hline $\begin{array}{l}\text { Unadjusted } \\
\text { Hands } \geq 2\end{array}$ & 1.281 & 3.60 & $1.57-8.27$ & 0.002 \\
\hline \multicolumn{5}{|l|}{ Adjusted } \\
\hline Hands $\geq 2$ & 1.320 & 3.74 & $1.45-9.68$ & 0.006 \\
\hline Age & 0.033 & 1.03 & $1.00-1.07$ & 0.033 \\
\hline Male gender & 0.053 & 1.05 & $0.41-2.67$ & 0.912 \\
\hline HD duration & -0.006 & 0.99 & $0.98-1.00$ & 0.087 \\
\hline Diabetes & 0.441 & 1.55 & $0.54-4.46$ & 0.413 \\
\hline Smoking & 0.048 & 1.04 & $0.35-3.17$ & 0.933 \\
\hline Ca levels & 0.140 & 1.15 & $0.59-2.23$ & 0.680 \\
\hline P levels & 0.010 & 1.01 & $0.68-1.49$ & 0.960 \\
\hline LDL-C & -0.001 & 0.99 & $0.98-1.01$ & 0.916 \\
\hline
\end{tabular}

${ }^{\text {a}}$ Pelvic periph, pelvic peripheral CS; hands, hands CS. Significant P values $(<0.05)$ are presented in bold. B is the regression coefficient.
Table 4. Association of clinical $\mathrm{PAD}$ with $\mathrm{VC}$ and $\mathrm{ABI}^{\mathrm{a}}$

\begin{tabular}{lllr}
\hline & $\begin{array}{l}\text { Without PAD } \\
(N=168)\end{array}$ & $\begin{array}{l}\text { With PAD } \\
(N=51)\end{array}$ & \multicolumn{1}{c}{$\mathrm{P}$} \\
\hline AACS & $4(8)$ & $\mathbf{8}(\mathbf{1 0})$ & $\mathbf{0 . 0 0 1}$ \\
SVCS & $2(4)$ & $\mathbf{4}(\mathbf{4})$ & $<\mathbf{0 . 0 0 1}$ \\
Iliac-femoral & $2(3)$ & $\mathbf{4}(\mathbf{2})$ & $<\mathbf{0 . 0 0 1}$ \\
Pelvic peripheral & $0(0)$ & $0(2)$ & 0.337 \\
Hands & $0(1)$ & $0(2)$ & 0.098 \\
ABI $<0.9(N=90)$ & $52(31 \%)$ & $\mathbf{3 8}(\mathbf{7 5 \%})$ & $<\mathbf{0 . 0 0 1}$ \\
ABI $0.9-1.3(N=87)$ & $80(48 \%)$ & $\mathbf{7}(\mathbf{1 4 \%})$ & $<\mathbf{0 . 0 0 1}$ \\
ABI $>1.3(N=42)$ & $36(21 \%)$ & $6(12 \%)$ & 0.185 \\
\hline
\end{tabular}

${ }^{\mathrm{a}} \mathrm{VCs}$ (median values with interquartile range) were compared with Kruskal-Wallis test; ABI groups were compared with Pearson chisquare test. Significant $\mathrm{P}$ values $(<0.05)$ are presented in bold.

$7.15(95 \%$ CI $2.05-24.86 ; \mathrm{P}=0.002)$ for $\mathrm{ABI}<0.9$ and $5.08(95 \%$ CI 1.18-21.76; $\mathrm{P}=0.028)$ for $\mathrm{ABI}>1.3$, when compared with normal ABI.

\section{Discussion}

In this study, analysing $219 \mathrm{HD}$ patients, we have verified that both $\mathrm{ABI}<0.9$ or $\mathrm{ABI}>1.3$ were associated with all-cause and cardiovascular mortality. VC evaluated by plain X-ray in main arteries (aorta and iliac-femoral axis) were associated with an $\mathrm{ABI}<0.9$, while $\mathrm{VC}$ evaluated 
Table 5. Association of $\mathrm{ABI}$ and $\mathrm{VC}$ with clinical PAD (binary regression) ${ }^{\mathrm{a}}$

\begin{tabular}{|c|c|c|c|c|}
\hline Dependent variable: clinical PAD & $B$ & OR & $95 \% \mathrm{CI}$ & $\mathrm{P}$ \\
\hline \multicolumn{5}{|l|}{$\mathrm{ABI}<0.9$} \\
\hline Unadjusted & 1.875 & 6.52 & $3.21-13.26$ & $<0.001$ \\
\hline Adjusted & 1.799 & 6.04 & $2.83-12.86$ & $<0.001$ \\
\hline \multicolumn{5}{|l|}{ ABI $0.9-1.3$} \\
\hline Unadjusted & -1.743 & 0.18 & $0.75-0.41$ & $<0.001$ \\
\hline Adjusted & -1.517 & 0.22 & $0.90-0.64$ & 0.001 \\
\hline \multicolumn{5}{|l|}{$\mathrm{ABI}>1.3$} \\
\hline Unadjusted & -0.716 & 0.48 & $0.19-1.23$ & 0.131 \\
\hline Adjusted & -0.988 & 0.372 & $0.14-1.01$ & 0.052 \\
\hline \multicolumn{5}{|l|}{ AACS $\geq 6$} \\
\hline Unadjusted & 0.849 & 2.34 & $1.23-4.44$ & 0.010 \\
\hline Adjusted & 0.697 & 2.01 & $0.99-4.04$ & 0.051 \\
\hline \multicolumn{5}{|l|}{ SVCS3> } \\
\hline Unadjusted & 1.371 & 3.94 & $2.01-7.69$ & $<0.001$ \\
\hline Adjusted & 1.142 & 3.13 & $1.48-6.59$ & 0.003 \\
\hline \multicolumn{5}{|l|}{ Ileo-femoral CS $\geq 2$} \\
\hline Unadjusted & 1.469 & 4.35 & $1.99-9.48$ & $<0.001$ \\
\hline Adjusted & 1,24 & 3.45 & $1.49-8.03$ & 0.004 \\
\hline \multicolumn{5}{|l|}{ Pelvic periph $\mathrm{CS} \geq 2$} \\
\hline Unadjusted & 0.224 & 1.25 & $0.614-2.55$ & 0.537 \\
\hline Adjusted & -0.015 & 0.98 & $0.44-2.19$ & 0.986 \\
\hline \multicolumn{5}{|l|}{ Hands CS $>2$} \\
\hline Unadjusted & 0.537 & 1.71 & $0.86-3.39$ & 0.125 \\
\hline Adjusted & 0.423 & 1.53 & $0.71-3.29$ & 0.282 \\
\hline
\end{tabular}

${ }^{a}$ All models were adjusted to age, HD duration, male gender, diabetes, smoking habits, $\mathrm{Ca}, \mathrm{P}$ and LDL levels. Significant $\mathrm{P}$ values $(<0.05)$ are presented in bold. B is the regression coefficient.

in peripheral and distal arteries were associated with an ABI $>1.3$. Hyperphosphataemia $[1,10]$ and hypercalcaemia [1] have been associated with amputations suggesting a probable contribution of VC to PAD [1]. Wong et al. [11] have recently demonstrated that abdominal aortic calcification in the general population was associated with low ABI. To our knowledge, our study is the first to demonstrate, in dialysis patients, an association between VC evaluated by plain X-ray with low or high $\mathrm{ABI}$ and to show that this association is related with the anatomical distribution of VC.

Lehto et al. [12] and London et al. [13] have previously correlated the two histological types of $\mathrm{VC}$, intimal and medial calcification, with a specific radiological pattern: patchy and irregular for intimal calcification and continuous and linear for medial calcification. Intimal and medial calcification may vary according to the type of vessel: large elastic arteries versus the smaller muscular type artery and proximal versus distal sites of the arterial tree [14]. In our study, we have decided to classify VC by their anatomical distribution because this classification is very simple to apply and is not operator dependent.

In several published series $[1,3-7]$, there is a wide variance among different countries in the prevalence of amputations (1.7-10\%), clinical PAD (12-39.7\%) and low ABI (15.5-38.3\%) with lower values consistently observed in Japan. In our study, we have verified an ABI $<0.9$ and $>1.3$, respectively, in 41 and $19 \%$ of patients; only $40 \%$ of the population showed a normal ABI. Age and VC were directly associated with low or high $\mathrm{ABI}$ and this may explain the high prevalence of an abnormal ABI in this elderly group of patients with widespread VC.

We have previously demonstrated that VC evaluated in plain X-ray were associated with higher risk of clinical PAD [9]. In the present study, we have verified that VC in the main arteries and low ABI were associated with higher risk of clinical PAD. However, there were also many patients with low ABI values without PAD symptoms. This discrepancy between ABI results and clinical diagnosis of PAD has been previously described [7] and points out the usefulness of $A B I$ evaluation to identify PAD in asymptomatic patients. In dialysis patients, the first sign of PAD is frequently a non-healing ischaemic ulcer [7].

\section{All-Cause Mortality}

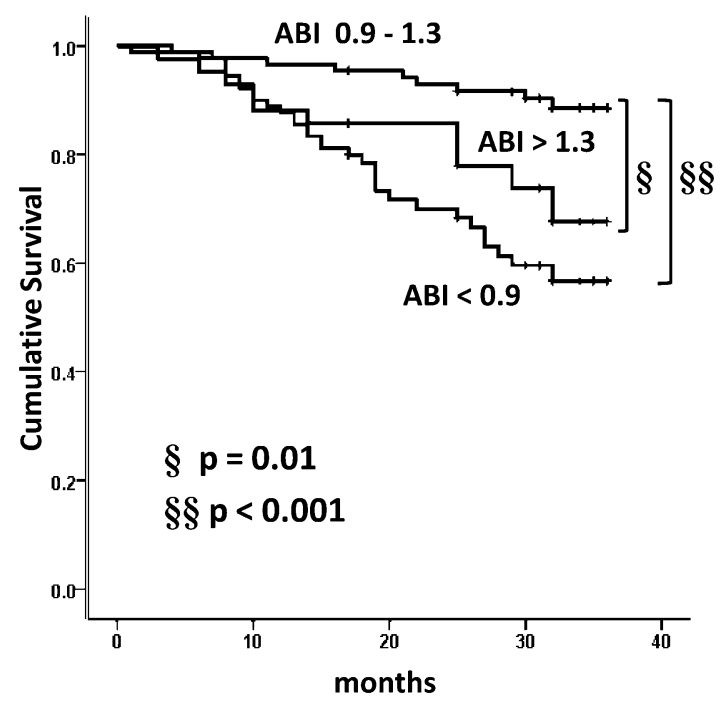

\section{Cardiovascular Mortality}

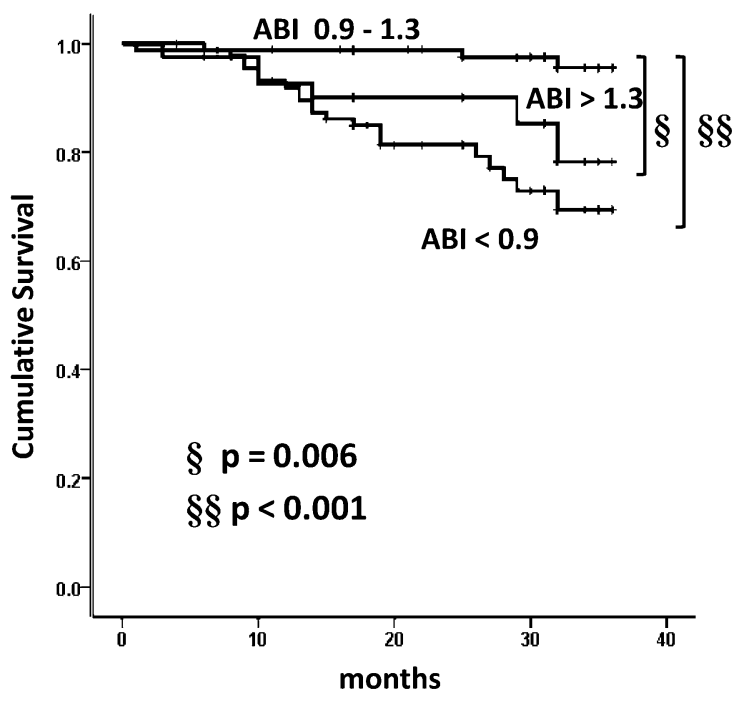

Fig. 3. Survival by Ankle-Brachial-Index 
Table 6. $\mathrm{ABI}<0.9$ and survival (cox regression) ${ }^{\mathrm{a}}$

\begin{tabular}{lrrrr}
\hline & $B$ & HR & $95 \%$ CI & P \\
\hline All cause mortality & & & & \\
Unadjusted & 1.552 & 4.72 & $2.23-9.97$ & $<\mathbf{0 . 0 0 1}$ \\
$\quad$ ABI $<0.9$ & & & & \\
Adjusted & & & & \\
ABI $<0.9$ & 1.374 & 3.95 & $1.83-8.51$ & $<\mathbf{0 . 0 0 1}$ \\
Age & 0.039 & 1.04 & $1.01-1.07$ & $\mathbf{0 . 0 0 8}$ \\
HD duration & 0.004 & 1.00 & $1.00-1.01$ & 0.063 \\
P levels & 0.017 & 1.02 & $0.76-1.37$ & 0.909 \\
Diabetes & 0.692 & 1.99 & $0.90-4.42$ & 0.088 \\
CV disease & -0.374 & 0.68 & $0.36-1.33$ & 0.266 \\
CV mortality & & & & \\
Unadjusted & & & & \\
ABI $<0.9$ & 2.212 & 9.14 & $2.69-30.98$ & $<\mathbf{0 . 0 0 1}$ \\
Adjusted & & & & \\
ABI $<0.9$ & 1.967 & 7.15 & $2.05-24.86$ & $\mathbf{0 . 0 0 2}$ \\
Age & 0.032 & 1.03 & $0.99-1.07$ & 0.117 \\
HD duration & 0.002 & 1.00 & $0.99-1.01$ & 0.549 \\
P levels & -0.050 & 0.95 & $0.64-1.42$ & 0.808 \\
Diabetes & 0.846 & 2.33 & $0.83-6.58$ & 0.110 \\
CV disease & 0.307 & 1.36 & $0.57-3.19$ & 0.481 \\
\hline
\end{tabular}

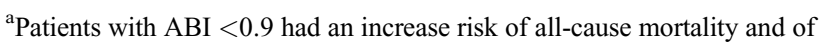
cardiovascular mortality. Significant $\mathrm{P}$ values $(<0.05)$ are presented in bold. $\mathrm{B}$ is the regression coefficient.

Table 7. $\mathrm{ABI}>1.3$ and survival $(\text { cox regression })^{\mathrm{a}}$

\begin{tabular}{lllll}
\hline & $B$ & HR & $95 \%$ CI & $\mathrm{P}$ \\
\hline All cause mortality & & & & \\
$\quad$ Unadjusted & & & & \\
$\quad$ ABI $>1.3$ & 1.128 & 2.65 & $1.05-6.73$ & $\mathbf{0 . 0 1 5}$ \\
Adjusted & & & & \\
$\quad$ ABI $>1.3$ & 0.995 & 2.71 & $1.06-6.93$ & $\mathbf{0 . 0 3 8}$ \\
Age & 0.027 & 1.03 & $0.98-1.07$ & 0.175 \\
HD duration & 0.006 & 1.01 & $1.00-1.01$ & $\mathbf{0 . 0 2 4}$ \\
P levels & & & & \\
Diabetes & 0.481 & 1.62 & $0.54-4.88$ & 0.393 \\
$\quad$ CV disease & 0.416 & 1.52 & $0.58-3.96$ & 0.396 \\
CV mortality & & & & \\
Unadjusted & & & & \\
$\quad$ ABI $>1.3$ & 1.734 & 5.66 & $1.39-22.96$ & $\mathbf{0 . 0 1 5}$ \\
Adjusted & & & & \\
ABI $>1.3$ & 1.628 & 5.08 & $1.18-21.76$ & $\mathbf{0 . 0 2 8}$ \\
Age & 0.022 & 1.02 & $0.96-1.08$ & 0.446 \\
HD duration & 0.007 & 1.01 & $0.99-1.02$ & 0.082 \\
$\quad$ P levels & 0.052 & 1.05 & $0.56-1.96$ & 0.870 \\
$\quad$ Diabetes & 0.655 & 1.92 & $0.42-8.84$ & 0.400 \\
CV disease & 1.290 & 3.63 & $0.792-16.67$ & 0.097 \\
\hline
\end{tabular}

${ }^{\text {a }}$ Patients with $\mathrm{ABI}>1.3$ had an increase risk of all-cause mortality and of cardiovascular mortality. Significant $\mathrm{P}$ values $(<0.05)$ are presented in bold. B is the regression coefficient.

In our study, $\mathrm{VC}$ in peripheral and distal arteries and $\mathrm{ABI}>1.3$ were not associated with clinical PAD. A high $\mathrm{ABI}$ is the result of noncompressible peripheral arteries but high $\mathrm{ABI}$ may mask a more proximal stenosis and cannot exclude the presence of PAD [15]. In this situation, the toe-brachial index is a cost-effective way to establish or refute PAD [16]. In a group of HD patients with high prevalence of both diabetes and clinical PAD, Ohtake et al. [17] demonstrated for the first time that below-knee arterial calcifications were associated with low toe-brachial index and both factors were independent predictors of clinical PAD.

In the general population [15], as well as in dialysis patients [3-5], low ABI has been associated with lower survival. In our study, we have also confirmed this same association. In addition, like Ono et al. [3] and Chen et al. [4], we have also verified that an $\mathrm{ABI}>1.3$ was associated with higher risk of mortality. In non-CKD patients, $\mathrm{ABI}$ $>1.3$ has also been associated with increased cardiovascular morbidity [18] and with greater left ventricular mass [19].

In summary, in our study, we have verified that abnormal $\mathrm{ABI}$ is highly prevalent in dialysis patients and both low and high ABI were associated with all-cause and cardiovascular mortality. VC in large arteries were associated with low $\mathrm{ABI}$ and clinical PAD, while $\mathrm{VC}$ in peripheral and distal arteries were associated with high ABI. ABI is a simple and noninvasive method that can be performed at bedside and that allows the identification of high cardiovascular risk patients. The hypothesis that the correction of factors associated with the development of VC might have an impact on PAD outcomes needs to be evaluated.

Acknowledgements. We would like to thank all the Medical Directors of the Haemodialysis Clinics that have participated in this study: Acácio Pita Negrao, Helena Boquinhas, Domingos Machado, Odete Pereira, Edgar de Almeida, José Barbas and Rui Castro.

The authors thank ISNI, Instituto Nefrológico de Investigaçao, for the assistance in the organization of this study. This study was supported by a grant from Genzyme.

Conflict of interest statement. T.A. has received research grants from Genzyme, lecture fees from Amgen, Genzyme, Abbot and Novartis and consultancy fees from Genzyme, Abbot, Amgen and Shire. The other authors have no conflict of interest of any type (personal, commercial, political, academic or financial) in the elaboration and presentation of this work.

\section{References}

1. Combe C, Albert JM, Bragg-Gresham JL et al. The burden of amputation among hemodialysis patients in the Dialysis Outcomes and Practice Patterns Study (DOPPS). Am J Kidney Dis 2009; 54: 680-692

2. Fowkes FG, Murray GD, Butcher I et al. Ankle Brachial Index Collaboration. Ankle brachial index combined with Framingham Risk Score to predict cardiovascular events and mortality: a meta-analysis. JAMA 2008; 300: 197-208

3. Ono K, Tsuchida A, Kawai $\mathrm{H}$ et al. Ankle-brachial blood pressure index predicts all-cause and cardiovascular mortality in hemodialysis patients. J Am Soc Nephrol 2003; 14: 1591-1598

4. Chen SC, Chang JM, Hwang SJ et al. Ankle brachial index as a predictor for mortality in patients with chronic kidney disease and undergoing hemodialysis. Nephrology (Carlton) 2010; 15: 294-299

5. Liu JH, Lin HH, Yang YF et al. Subclinical peripheral artery disease in patients undergoing peritoneal dialysis: risk factors and outcome. Perit Dial Int 2009; 29: 64-71

6. Chen SC, Chang JM, Hwang SJ et al. Significant correlation between ankle-brachial index and vascular access failure in hemodialysis patients. Clin J Am Soc Nephrol 2009; 4: 128-134

7. O'Hare AM, Johansen K. Lower-extremity peripheral arterial disease among patients with end-stage renal disease. J Am Soc Nephrol 2001; 12: $2838-2847$ 
8. Kauppila LI, Polak JF, Cupples LA et al. New indices to classify location, severity and progression of calcific lesions in the abdominal aorta: a 25-year follow-up study. Atherosclerosis 1997; 132: $245-250$

9. Adragao T, Pires A, Lucas C et al. A simple vascular calcification score predicts cardiovascular risk in haemodialysis patients. Nephrol Dial Transplant 2004; 19: 1480-1488

10. O'Hare AM, Bacchetti P, Segal M et al. Factors associated with future amputation among patients undergoing hemodialysis: results from the Dialysis Morbidity and Mortality Study Waves 3 and 4. Am J Kidney Dis 2003; 41: 162-170

11. Wong ND, Lopez VA, Allison M et al. Abdominal aortic calcium and multi-site atherosclerosis: the multiethnic study of atherosclerosis. Atherosclerosis 2011; 214: 436-441

12. Lehto $\mathrm{S}$, Niskanen $\mathrm{L}$, Suhonen $\mathrm{M}$ et al. Medial artery calcification. A neglected harbinger of cardiovascular complications in noninsulin-dependent diabetes mellitus. Arterioscler Thromb Vasc Biol 1996; 16: 978-983

13. London GM, Guérin AP, Marchais SJ et al. Arterial media calcification in end-stage renal disease: impact on all-cause and cardiovascular mortality. Nephrol Dial Transplant 2003; 18: 1731-1740
14. Amann K. Media calcification and intima calcification are distinct entities in chronic kidney disease. Clin J Am Soc Nephrol 2008; 3: 1599-1605

15. Heald CL, Fowkes FG, Murray GD et al. Risk of mortality and cardiovascular disease associated with the ankle-brachial index: systematic review. Atherosclerosis 2006; 189: 61-69

16. Hirsch AT, Haskal ZJ, Hertzer NR et al. ACC/AHA guidelines for the management of patients with peripheral arterial disease (lower extremity, renal, mesenteric, and abdominal aortic): a collaborative report. J Vasc Interv Radiol 2006; 17: 1383-1397

17. Ohtake T, Oka M, Ikee R et al. Impact of lower limbs' arterial calcification on the prevalence and severity of PAD in patients on hemodialysis. J Vasc Surg 2011; 53: 676-683

18. Allison MA, Hiatt WR, Hirsch AT et al. A high ankle-brachial index is associated with increased cardiovascular disease morbidity and lower quality of life. J Am Coll Cardiol 2008; 51: 1292-1298

19. Ix JH, Katz R, Peralta CA et al. A high ankle brachial index is associated with greater left ventricular mass MESA (Multi-Ethnic Study of Atherosclerosis). J Am Coll Cardiol 2010; 55: 342-349

Received for publication: 1.2.11; Accepted in revised form: 1.4.11 